\title{
La investigación biomédica en el contexto de la Ley $\mathrm{N}^{\circ} \mathbf{2 0 . 5 8 4}$ Biomedical research in the context of low $\mathrm{N}^{\circ} 20,584$
}

$\mathrm{L}$ a Revista Chilena de Neuro-Psiquiatría es el órgano oficial de expresión científica de la Sociedad de Neurología Psiquiatría y Neurocirugía de Chile y tiene como misión publicar artículos de investigación sobre aspectos básicos y clínicos de las tres especialidades.

A los numerosos desafíos que debe enfrentar nuestra revista para poder seguir cumpliendo con su misión, desafíos comentados en la Editorial del número precedente (Presente y Futuro de nuestra revista, Año 68, VOL 52, Nº 1, Enero-Marzo 2014, pp 7-8), se ha sumado otro de la mayor seriedad, y que no ha recibido, en nuestra opinión, la atención que se merece. Nos referimos a los efectos sobre la investigación biomédica de la ley 20.584 que REGULA LOS DERECHOS Y DEBERES QUE TIENEN LAS PERSONAS EN RELACIÓN CON ACCIONES VINCULADAS A SU ATENCIÓN EN SALUD, publicada el 24 de Abril de 2012. Tres artículos de esta ley, los artículos 13, 21 y 28, impiden o afectan significativamente el desarrollo de la investigación científica en el área de la salud. De especial interés para nuestra revista es el artículo 28 que regula la investigación científica en personas con discapacidad psíquica o intelectual producida por variadas patologías neurológicas, psiquiátricas o neuroquirúrgicas. ¿Qué normas establece este nuevo marco regulatorio y de qué modo afectan a la investigación biomédica en nuestro país?

\section{Investigación en Fichas Clínicas}

\section{Párrafo $5^{\circ}$ \\ De la reserva de la información contenida en la ficha clínica.}

\section{Artículo 13}

"Los terceros que no estén directamente relacionados con la atención de salud de la persona no tendrán acceso a la información concentida en la respectiva ficha clínica. Ello incluye al personal de salud y administrativo del mismo prestador, no vinculados con la atención de la persona".

"Un tercero podrá tener acceso a la ficha clínica sólo debidamente autorizado por el titular mediante poder simple otorgado ante notario" (el subrayado es nuestro).

Debido a que el investigador clínico es formalmente un tercero respecto a la atención del paciente, con esta indicación se hace prácticamente imposible toda investigación basada en la revisión de fichas clínicas. En efecto, son evidentes las dificultades que estarían asociadas a la obtención por cada paciente de un permiso notarial para estos efectos: costos económicos y de tiempo para el paciente, identificación y localización de cada paciente para indicarle y motivarlo a la realización de la tramitación del permiso notarial, etc.

No se entiende la razón por la cual, para proteger los derechos del paciente, se requiere, además de la firma de un consentimiento informado, la obtención de un poder notarial cuyo objetivo sería el mismo del consentimiento, a saber, autorizar al acceso de la ficha clínica del paciente, duplicando así de manera innecesaria dos acciones para un mismo fin.

Debido a que las investigaciones basadas en la revisión de las fichas clínicas no generan por definición ningún nuevo dato que los ya obtenidos en las atenciones médicas previas a las cuales el paciente ya consintió, debería discutirse si estos estudios requieren de un consentimiento informado específico o si es suficiente el consentimiento que los pacientes otorgan para la realización habitual de la práctica médica. En nuestra opinión sería sólo necesario que un protocolo de investigación basada en la revisión de las fichas clínicas estuviera aprobado por un comité de ética para que este pudiera realizarse. 


\section{Investigación en personas que están por nacer, recién nacidos y niños}

\author{
Párrafo 7 \\ De la protección de la autonomía de las personas \\ que participan en investigación científica.
}

\section{Artículo 21}

"Toda persona deberá ser informada y tendrá derecho a elegir su incorporación en cualquier tipo de investigación científica biomédica, en los términos de la ley $\mathrm{N}^{\circ} 20.120$. Su expresión de voluntad deberá ser previa, expresa, libre, informada, personal y constar por escrito" (el subrayado es nuestro).

Es evidente que de acuerdo a este artículo no se puede realizar investigación en personas sanas o enfermas que no puedan expresar su voluntad personalmente. Las personas afectas a esta regulación son: las personas que están por nacer, los recién nacidos, y los niños hasta una etapa imposible de determinar con claridad. En consecuencia, dejando de lado el caso de personas analfabetas, no son permitidas las investigaciones biomédicas en biología y fisiopatología fetal, en neonatología y en un vasto campo de la pediatría, ya que estas personas no pueden otorgar un consentimiento personal, y como veremos más adelante, el artículo 28 de la ley que comentamos, prohíbe además la investigación científica en personas con discapacidad psíquica o intelectual que no puedan expresar su voluntad.

Los diversos códigos internacionales de ética de la investigación biomédica han siempre reconocido que en el caso de las personas incapaces de otorgar un consentimiento informado, un representante legalmente válido puede, cumpliéndose otras exigencias, otorgar tal consentimiento. Así por ejemplo, la Declaración de Helsinki de la Asociación Médica Mundial en su última enmienda (64a Asamblea General, Fortaleza, Brasil, octubre de 2013), en su artículo 28, establece que: "Cuando el individuo potencial sea incapaz de dar su consentimiento informado, el médico debe pedir el consentimiento informado del representante legal".

No se entiende la razón por la cual esta nueva ley no permita que un representante legalmente válido de un paciente incapaz de consentir pueda otorgar la autorización para que dichas personas participen en una investigación biomédica. Quisiéramos notar que el concepto del consentimiento informado del este artículo 21 parece estar en contradicción con la doctrina del consentimiento informado que la legislación chilena establece para la donación de órganos en casos de muerte encefálica. En efecto, el artículo 10 de la ley 19.451 que ESTABLECE LAS NORMAS SOBRE TRASPLANTE Y DONACIÓN DE ÓRGANOS, estipula que: "Se podrá efectuar trasplante de órganos de personas en estado de muerte que, en vida, no hayan expresado su autorización para ello en los términos de esta ley, así como de personas menores de edad o legalmente incapaces, siempre que ello sea autorizado por su cónyuge o, en subsidio, por su representante legal. A falta de ambos, la autorización deberá otorgarse por la mayoría de los parientes consanguíneos presentes de grado más próximo en la línea recta o, de no haberlos, por la mayoría de los parientes consanguíneos presentes de grado más próximo en la línea colateral, estos últimos hasta el tercer grado inclusive".

La responsabilidad moral y el derecho reconocido por esta ley de trasplantes a familiares de distinto grado para otorgar el consentimiento para la obtención de órganos en casos de muerte encefálica de personas menores de edad o legalmente incapaces, no parece coherente con la negación de ese mismo derecho en el caso de investigación.

\section{Investigación en personas con discapacidad psíquica o intelectual}

Finalmente, el artículo 28 de la ley que comentamos, regula la investigación científica en las personas que esa ley denomina con "discapacidad psíquica o intelectual”.

\section{Párrafo $8^{\circ}$}

De los derechos de las personas con discapacidad psíquica o intelectual.

\section{Artículo 28}

"Ninguna persona con discapacidad psíquica o 
intelectual que no pueda expresar su voluntad podrá participar en una investigación científica".

"En los casos en que se realice investigación científica con participación de personas con discapacidad psíquica o intelectual que tengan la capacidad de manifestar su voluntad y que hayan dado consentimiento informado, además de la evaluación ético científica que corresponda, será necesaria la autorización de la Autoridad Sanitaria competente, además de la manifestación de voluntad expresa de participar tanto de parte del paciente como de su representante legal".

De acuerdo a este artículo, en nuestro país, no se pueden realizar estudios en recién nacidos o niños con síndrome de Down, en pacientes con retardo o demencias severas, en pacientes con distintas formas de psicosis, en pacientes afásicos, en la fase aguda del Traumatismo Encéfalo Craneano y del Accidente Vascular Cerebral en pacientes con alteración de conciencia, por nombrar sólo algunos ejemplos de patología cerebral o mental asociada a una incapacidad "psíquica" o "intelectual" que se asocian al hecho de impedir la expresión de la voluntad.

Es llamativo, que esta ley no defina lo que entiende por "discapacidad psíquica o intelectual", ni explique la diferencia que podría existir entre una discapacidad "psíquica" y otra "intelectual", dejando así al arbitrio de las entidades regulatorias, comités de ética por ejemplo, el juicio sobre que patologías, o grado de severidad de las mismas, tendría como efecto producir una "discapacidad psíquica o intelectual”. Sin embargo, parece más arbitraria aún la posibilidad de discriminar entre las personas que padeciendo este tipo de discapacidad puedan o no puedan expresar su voluntad.

Es posible que frente a la dificultad de definir de manera clara estos términos el legislador haya decidido no definirlos. Pero la consecuencia de tal ausencia es una reglamentación vacía de contenidos precisos con la evidente imposibilidad de regular el complejo y variado mundo práctico que toda reglamentación debe poder iluminar sin ambigüedad.

El problema principal de esta nueva reglamentación es la injusta discriminación que produce con las mismas personas que ella aparentemente inten- ta proteger. En efecto, al impedir que las personas con discapacidad psíquica o intelectual que no puedan expresar su voluntad puedan participar en una investigación científica, impide por principio el progreso del conocimiento médico que puede ayudar a esas mismas personas que por padecer una determinada patología mental o cerebral se encuentran discapacitadas psíquica o intelectualmente. ¿Cómo puede progresar el conocimiento de las patologías asociadas a este tipo de discapacidad sino es posible desarrollar estudios sobre ellas?

Si esta ley fuera una ley con validez universal se establecería el principio de la total y más completa ignorancia sobre esas patologías, condenando a los portadores de las mismas a no recibir nunca los beneficios del progreso científico y médico, del cual sí gozarían los enfermos que por ventura no tienen una patología mental o cerebral causante de una discapacidad psíquica o intelectual que le impida expresar su voluntad.

Es por todos aceptado que las personas con discapacidad psíquica o intelectual constituyen una población vulnerable cuyos derechos deben ser especialmente protegidos. Así, por ejemplo, lo reconoce la Declaración de Helsinki de la Asociación Médica Mundial (64a Asamblea General, Fortaleza, Brasil, octubre de 2013), que en su artículo 28, citado más arriba, además de establecer la validez del consentimiento por un representante del paciente incapaz de consentir, enumera las condiciones que debe reunir la investigación científica en esas mismas personas para ser aceptables desde un punto de vista ético: "Estas personas no deben ser incluidas en la investigación que no tenga posibilidades de beneficio para ellas, a menos que ésta tenga como objetivo promover la salud del grupo representado por el individuo potencial y esta investigación no puede realizarse en personas capaces de dar su consentimiento informado y la investigación implica sólo un riesgo y costo mínimos".

De este modo, para la Declaración de Helsinki, y para todos los códigos internacionales de ética de la investigación biomédica, el principio básico que debe guiar la investigación en personas incapaces de consentir es que en ellas no deben realizarse investigaciones si tales investigaciones puedan hacer- 
se en personas que puedan dar su consentimiento.

Es difícil de entender que la nueva legislación chilena sobre estos aspectos se aleje, sin razones explicitadas, de los grandes principios de la ética de la investigación científica reconocidos universalmente.

Tal como lo expresara recientemente el Directorio de la Sociedad de Epileptología de Chile, en su carta a las autoridades del país (Revista Chilena de Epilepsia, Año 13, Nº 3. Diciembre 2013, p 87), los artículos antes citados de esta ley "representan un importante obstáculo para el desarrollo de la investigación clínica en nuestros pacientes".

Por lo anterior, creemos urgente que a la brevedad todos los involucrados, especialmente las nuevas autoridades del país, puedan corregir las normas de esta ley que regulan la investigación científica.

Manuel Lavados 